\title{
Assessment of Vertical Skeletal Patterns using a New Cephalometric Parameter: The Dhaval-Rohan Angle
}

\author{
${ }^{1}$ Dhaval Ranjitbhai Lekhadia, ${ }^{2}$ Rohan Rai, ${ }^{3}$ Niveditha Hegde, ${ }^{4}$ Gautham Hegde, ${ }^{5}$ Abhinay Sorake, ${ }^{6}$ Anil Kumar
}

\begin{abstract}
Introduction: The aim of this study was to establish a new cephalometric parameter, named the Dhaval-Rohan angle (DR), to assess the vertical skeletal patterns on a lateral cephalogram with accuracy and reproducibility.

Materials and methods: One hundred and twenty pretreatment lateral cephalograms of the patients visiting the department of orthodontics and dentofacial orthopedics for treatment were obtained and divided into three groups. i.e., horizontal growth pattern, average growth pattern, and vertical growth pattern cases based on the routinely used cephalometric parameters; FMA, SN-GoGn, Y-axis angle and Jarabak ratio. This angle uses three skeletal landmarks, the point $\mathrm{C}$ (center of the condyle), point $\mathrm{M}$ (midpoint of premaxilla), and point $\mathrm{G}$ (center of the largest circle that is tangent to the internal inferior, anterior, and posterior surfaces of the mandibular symphysis).
\end{abstract}

Results: The one-way analysis of variance (ANOVA) test showed that the three groups studied were not the same for DR angle and the post hoc Tukey test found the groups to be significantly different. According to the Student's t-test, there was no statistically significant difference in mean values of DR angle between males and females.

Conclusion: Cephalometric evaluation of young adults shows that the DR angle below $28.5^{\circ}$ indicates a horizontal growth pattern, between 28.5 and $32.5^{\circ}$ indicate an average growth pattern and above $32.5^{\circ}$ indicate a vertical growth pattern.

Keywords: Growth pattern, Point C, Point G, Point M.

How to cite this article: Lekhadia DR, Rai R, Hegde N, Hegde G, Sorake A, Kumar A. Assessment of Vertical Skeletal Patterns using a New Cephalometric Parameter: The Dhaval-Rohan Angle. J Postgrad Med Edu Res 2017;51(1):7-11.

Source of support: Nil

Conflict of interest: None

\section{INTRODUCTION}

The contribution toward growth of the human face is multifactorial. ${ }^{1,2}$ The altered growth pattern has an important role to play in a face with increased vertical vector

\footnotetext{
${ }^{1}$ Postgraduate Student, ${ }^{2} \mathrm{Head},{ }^{3-6}$ Assistant Professor

${ }^{1-6}$ Department of Orthodontics and Dentofacial Orthopedics, A J Institute of Dental Sciences, Rajiv Gandhi University of Health Sciences, Mangaluru, Karnataka, India

Corresponding Author: Dhaval Ranjitbhai Lekhadia, Postgraduate Student, Department of Orthodontics and Dentofacial Orthopedics A J Institute of Dental Sciences, Rajiv Gandhi University of Health Sciences, Mangaluru, Karnataka, India, Phone: +91-9916383464 e-mail: drdhavalekhadia@gmail.com
}

of growth. An accurate assessment of the vertical skeletal pattern in orthodontic diagnosis and treatment planning is critically important. Depending on the growth pattern diagnosed, specific treatment mechanics are planned. It was not until Sassouni's ${ }^{3}$ description of "skeletal open bite" in the 1960s that excessive vertical development of the face began to receive any emphasis in cephalometric diagnosis. Various parameters were put forward by authors to evaluate the growth pattern of an individual. Of these, FMA, ${ }^{4}$ SN-GoGn, ${ }^{5}$ Y-axis angle, ${ }^{6}$ Facial axis angle, ${ }^{7}$ and Jarabak ratio $^{8}$ are the routinely used parameters. The drawbacks of these parameters were explained by Rizwan et al in $2011 .^{9}$

To overcome these difficulties, we developed a new parameter, the DR angle. The DR angle is a cephalometric measurement for assessing the vertical skeletal pattern of an individual. Three skeletal landmarks were used:

1. Point C: The center of the condyle, found by tracing the head of the condyle, and approximating its center.

2. Point M: Midpoint of premaxilla, obtained by forming the best fit circle that was tangent to the superior, anterior, and palatal surfaces of the maxilla and then approximating its center.

3. Point G: Center of the largest circle that is tangent to the internal inferior, anterior, and posterior surfaces of the mandibular symphysis.

\section{How to construct DR Angle (Fig. 1)}

- First step: A line connecting from point $\mathrm{C}$ to point $\mathrm{M}$

- Second step: A line connecting from point $\mathrm{C}$ to point $\mathrm{G}$

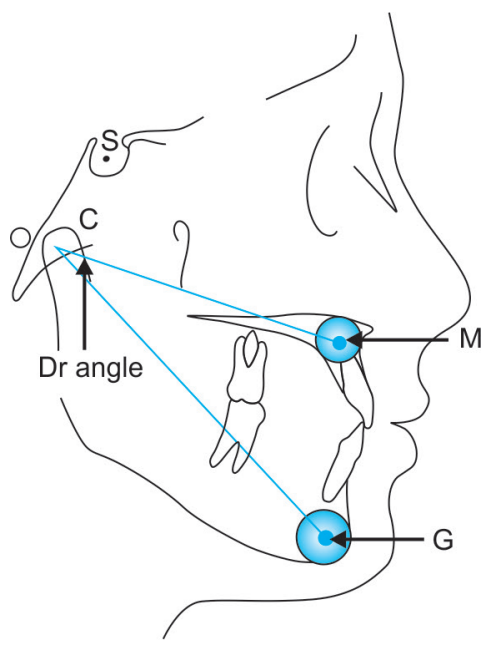

Fig. 1: Dhaval-Rohan angle 
The angle at point $C$ between $C M$ axis and $C G$ axis is the DR angle.

The goal of this study was to evaluate the vertical skeletal patterns using DR angle. This study was done to define the mean value and standard deviation (SD) of DR angle in people with average growth pattern. Moreover, also to corroborate any statistically significant difference between the mean values of DR angle in the three groups studied.

\section{MATERIALS AND METHODS}

One hundred and twenty pretreatment lateral cephalograms of Indian patients who visited the Department of Orthodontics and Dentofacial Orthopedics for treatment were obtained. The pretreatment lateral cephalograms were traced using acetate paper and $0.3 \mathrm{~mm}$ lead pencil. Once the lateral cephalograms were traced, the routinely used parameters to determine the growth pattern were constructed and measured by the same investigator to avoid interobserver errors. These parameters included: FMA, SN-GoGn, Y-axis angle, Facial axis angle and Jarabak ratio. Based on the above measurements, the sample was divided into three groups: Horizontal growth pattern, average growth pattern, and vertical growth pattern. The DR angle was individually constructed and measured on all the lateral cephalograms randomly to avoid bias. The values of DR angle obtained were statistically analysed to determine their significance and to find the cut off values to differentiate the three groups. The study design

Table 1: Analysis of variance test

\begin{tabular}{llllllr}
\hline & Groups & $n$ & Mean & SD & $F$ (ANOVA) & $p$-value \\
\hline DR angle & Horizontal & 33 & 27.3 & 2.43 & 47.486 & $<0.001$ \\
& Average & 63 & 30.48 & 1.391 & & \\
Vertical & 24 & 34.5 & 1.818 & & \\
\hline Total & 120 & 30.41 & 3.038 & & \\
\hline
\end{tabular}

ANOVA: Analysis of variance; DR: Dhaval-Rohan; SD: Standard deviation

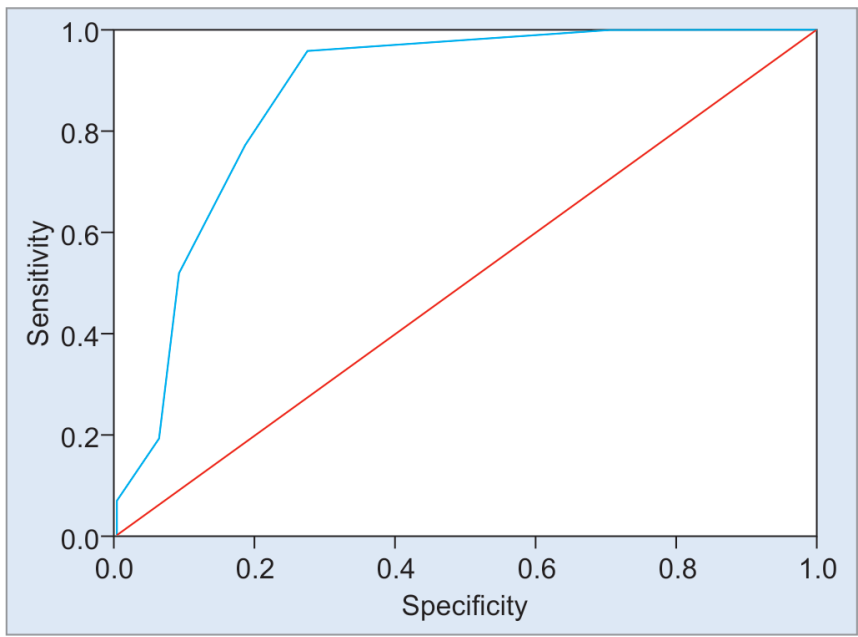

Graph 1: Receiver operating characteristic curve to differentiate horizontal from average growth pattern group was similar to Rizwan et al ${ }^{10}$ except that the sample was selected randomly to avoid operator bias. Out of 120 lateral cephalograms, 33 were of horizontal growers, 63 were of average growers, and 24 were of vertical growers.

\section{Inclusion Criteria}

- Adult patients with an age from 18 to 26 years

- All individuals with no apparent orofacial deformity, such as, cleft palate

- Acceptable quality radiographs.

\section{Exclusion Criteria}

- Apparent jaw fracture or surgical treatment

- History of orthodontic intervention.

\section{Statistical Analysis}

Microsoft excel was used to compile the data. The data were summarized as mean and SD. The one-way analysis of variance (ANOVA) test (Table 1), Student's t-test (Table 2) followed by post hoc Tukey test for comparison among three groups were done. Cutoff values were ascertained by receiver operating characteristic (ROC) curves to differentiate between horizontal and average growth pattern group (Graph 1) and between average and vertical growth pattern group (Graph 2). p-values less than 0.05

Table 2: Student's t-test to compare the DR angle values in males and females

\begin{tabular}{|c|c|c|c|c|c|c|}
\hline $\begin{array}{l}\text { Growth } \\
\text { pattern }\end{array}$ & & Sex & $n$ & Mean & $S D$ & $p$-value \\
\hline \multirow[t]{2}{*}{ Horizontal } & DR angle & $M$ & 6 & 27.2 & 2.168 & 0.6346 \\
\hline & & $F$ & 27 & 27.7 & 2.334 & \\
\hline \multirow[t]{2}{*}{ Average } & DR angle & M & 24 & 31.04 & 1.398 & 0.7502 \\
\hline & & $F$ & 40 & 31.15 & 1.292 & \\
\hline \multirow[t]{2}{*}{ Vertical } & DR angle & M & 8 & 35.38 & 2.066 & 0.096 \\
\hline & & $\mathrm{F}$ & 16 & 34.06 & 1.569 & \\
\hline
\end{tabular}

DR: Dhaval-Rohan; SD: Standard deviation

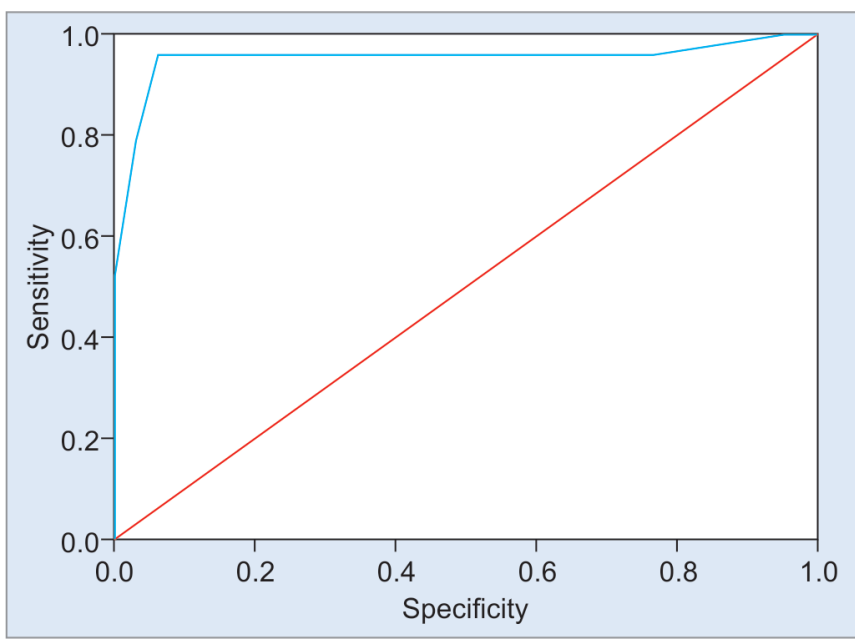

Graph 2: Receiver operating characteristic curve to differentiate average from vertical growth pattern group 
are considered significant. Statistical Package for the Social Sciences (SPSS) 20 is the software package used for statistical analysis.

\section{RESULTS}

It was found that all the parameters including DR angle were statistically significant. The one-way ANOVA test showed that the three groups were not the same for DR angle (Table 1). According to Student's t-test, there was no statistically significant difference between mean DR angle of males and females (Table 2) and post hoc Tukey test found the groups to be significantly different (Table 3 ). Area under the ROC curve for horizontal growth pattern group was 0.871 with a standard error of 0.044 (Table 4). Receiver operating characteristic curves showed that the DR angle less than $28.5^{\circ}$ has $95.30 \%$ sensitivity and $72.70 \%$ specificity to discriminate the horizontal growth pattern group from average growth pattern group (Table 5). Area under the ROC curve for vertical growth pattern group was 0.952 with a standard error of 0.036 (Table 6). DR angle more than $32.5^{\circ}$ showed $95.80 \%$ sensitivity and $93.70 \%$ specificity for discriminating average growth pattern group from vertical growth pattern group (Table 7).

Therefore, it can be predicted with a high degree of certainty that a patient with DR angle between 28.5 and $32.5^{\circ}$ truly has an average growth pattern, less than $28.5^{\circ}$ has a horizontal growth pattern and more than $32.5^{\circ}$ has a vertical growth pattern.

\section{DISCUSSION}

The derived point may, in some instances, better represent the true nature of the underlying skeletal pattern. Point $M$

Table 3: Post Hoc Tukey test

\begin{tabular}{lllcc}
\hline & & \multicolumn{3}{c}{ Subset for alpha $=0.05$} \\
\cline { 3 - 5 } Growth pattern & $n^{\mathrm{b}}$ & $1^{\mathrm{a}}$ & $2^{\mathrm{a}}$ & $3^{\mathrm{a}}$ \\
\hline Horizontal & 33 & 27.30 & 30.48 & \\
Average & 63 & & & 34.50 \\
Vertical & 24 & & 1.000 & 1.000 \\
Significance & & 1.000 & 1.000
\end{tabular}

Means for groups in homogeneous subsets are displayed; ${ }^{2}$ Uses harmonic mean sample size $=34.249 ;{ }^{\text {b}}$ The group sizes are unequal. The harmonic mean of the group sizes is used

Table 4: Area under the ROC curve to differentiate horizontal from average growth pattern group

\begin{tabular}{lllll}
\hline \multicolumn{3}{c}{ Test result variable(s): DR angle } \\
\hline & & \multicolumn{4}{c}{$\begin{array}{c}\text { Asymptotic } 95 \% \\
\text { confidence interval }\end{array}$} \\
\cline { 3 - 5 } Area under the & & Asymptotic & Lower & Upper \\
ROC curve & SE & significance & bound & bound \\
\hline 0.871 & 0.044 & $<0.001$ & 0.784 & 0.957 \\
\hline
\end{tabular}

ROC: Receiver operating characteristics; DR: Dhaval-Rohan; SE: Standard error
Table 5: Coordinates of the ROC curve to differentiate horizontal from average growth pattern group

\begin{tabular}{lll}
\hline \multicolumn{3}{c}{ Test result variable(s): DR angle } \\
\hline Positive if less than or equal to & Sensitivity (\%) & Specificity (\%) \\
\hline 22 & 100.00 & 0.00 \\
23.5 & 100.00 & 9.10 \\
24.5 & 100.00 & 18.20 \\
25.5 & 100.00 & 21.20 \\
26.5 & 100.00 & 27.30 \\
27.5 & 96.90 & 54.50 \\
$28.5^{*}$ & 95.30 & 72.70 \\
29.5 & 76.60 & 81.80 \\
30.5 & 51.60 & 90.90 \\
31.5 & 18.80 & 93.90 \\
32.5 & 6.30 & 100.00 \\
33.5 & 3.10 & 100.00 \\
35 & 0.00 & 100.00 \\
\hline
\end{tabular}

${ }^{*}$ Criterion responding with highest Youden index; ROC: Receiver operating characteristics; DR: Dhaval-Rohan

Table 6: Area under the ROC Curve to differentiate average from average vertical pattern group

\begin{tabular}{lllll}
\hline \multicolumn{3}{c}{ Test result variable(s): DR angle } \\
\hline & & \multicolumn{3}{c}{$\begin{array}{c}\text { Asymptotic } 95 \% \\
\text { confidence interval }\end{array}$} \\
\cline { 3 - 5 } Area under the & & Asymptotic & Lower & Upper \\
ROC curve & SE & significance & bound & bound \\
\hline 0.952 & 0.036 & $<0.001$ & 0.882 & 1.000 \\
\hline
\end{tabular}

ROC: Receiver operating characteristics; DR: Dhaval-Rohan; SE: Standard error

Table 7: Coordinates of the ROC curve to differentiate average from vertical growth pattern group

\begin{tabular}{lll}
\hline \multicolumn{3}{c}{ Test result variable(s): DR angle } \\
\hline Positive if greater than or equal to & Sensitivity (\%) & Specificity (\%) \\
\hline 26 & 100.00 & 0.00 \\
27.5 & 100.00 & 3.10 \\
28.5 & 100.00 & 4.70 \\
29.5 & 95.80 & 23.40 \\
30.5 & 95.80 & 48.40 \\
31.5 & 95.80 & 81.20 \\
$32.5^{*}$ & 95.80 & 93.70 \\
33.5 & 79.20 & 96.90 \\
34.5 & 50.00 & 100.00 \\
35.5 & 20.80 & 100.00 \\
36.5 & 8.30 & 100.00 \\
38 & 4.20 & 100.00 \\
40 & 0.00 & 100.00 \\
\hline
\end{tabular}

${ }^{*}$ Criterion responding with highest Youden index; ROC: Receiver operating characteristics; DR: Dhaval-Rohan

was defined by Nanda and Merill ${ }^{11}$ in 1994. It was also used effectively by Neela PK et al, ${ }^{12}$ Bhad WA et al, ${ }^{13}$ and Dave $\mathrm{HB}$ et $\mathrm{al}^{14}$ to introduce a new sagittal dysplasia indicator, the Yen angle, $\mathrm{W}$ angle, and HBN angle respectively. It was also used by Braun et al to study the growth 
vector in maxilla. ${ }^{15}$ Point $C$ was defined by Baik $C Y$ and Ververidou $\mathrm{M}^{16}$ in 2004 and effectively used to develop a new cephalometric measurement, the Beta angle. Point $\mathrm{G}$ was defined by Braun et $\mathrm{al}^{17}$ in 2004, which was also used effectively by various authors. ${ }^{12-14}$ The geometric location of these landmarks will allow for an accurate assessment of the vertical skeletal patterns.

In our study, we did not find any statistically significant difference in mean DR angle between males and females (Table 2). This was mainly due to the points used in this study. Braun et al ${ }^{15}$ studied the growth increments of maxilla using point $\mathrm{M}$ and found that the $\mathrm{C}$ - axis upto age 14 in males and females displays average yearly increments of 1.14 and $1.31 \mathrm{~mm} /$ year respectively. Another study done by Braun et $\mathrm{al}^{17}$ concluded that growth increments of mandible at point $\mathrm{G}$ by using $\mathrm{G}$-axis at 6 years in females and males were 97.8 and $97.6 \mathrm{~mm}$ respectively. Hence, no significant differences were found in mean DR angle of males and females.

A rough guide for classifying the accuracy of a diagnostic test was given by Metz $\mathrm{CE}^{18}$ in 1978. According to this guide, an area of 0.871 under the ROC curve is considered good for separating the horizontal from average growth pattern group (Table 4). An area under the ROC curve of 0.952 is considered excellent for separating the average from vertical growth pattern group (Table 6). In contrast, study done by Rizwan et al did not consider the areas under the ROC curves.

During cephalometric analysis, certain cases present with wide varied readings and not all the parameters to assess growth pattern, indicate a specific growth pattern. In such cases, the clinicians remain confused as to which parameter to rely on to determine the growth pattern. ${ }^{9}$ In such cases, DR angle can contribute to the existing cephalometric parameters to assess growth pattern of the case more accurately.

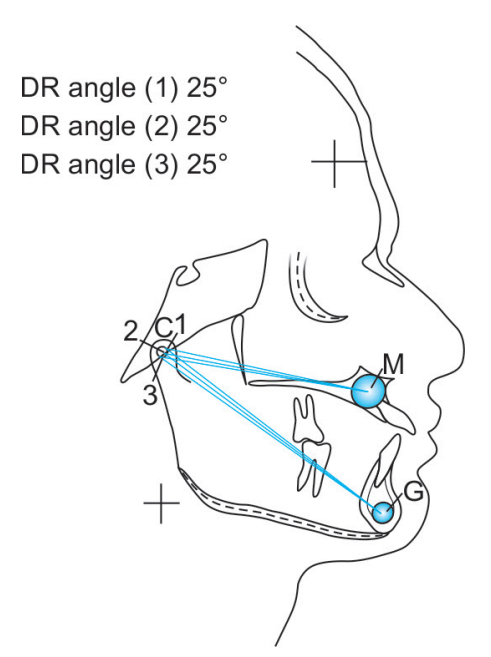

Fig. 2: Location of point $C$ in a radius of $2 \mathrm{~mm}$ circle from true center of the condyle in a horizontal grower does not affect the DR angle
The difficulty that might be encountered while using DR angle, is tracing the condyle precisely and locating its center, point $\mathrm{C}$. Cephalometric radiographs must be of high quality to locate the point $C$ accurately. Also, for locating point $\mathrm{M}$ and point $\mathrm{G}$, a template of concentric circles whose diameter increases by $1 \mathrm{~mm}$ successively is required which will add up to the armamentarium required for tracing and hence increases the time required to construct the DR angle.

Although, there is a disadvantage of using the center of the condyle, as discussed previously, the advantage of locating the center of the head of the condyle vs the condylion point, as used by McNamara, ${ }^{7}$ is that very precise tracing of the condyle is not really necessary. The clinician can visualize and approximate the center with a minimum error in DR angle as long as that point is within $2 \mathrm{~mm}$ radius of its actual location. As shown in Figs 2 to 4 , if the true center of the condyle is at point $C$, but if the clinician locates it within a circle of $2 \mathrm{~mm}$ radius, then DR angle is not affected at all in all the three groups; this makes it use still acceptable.

This technique is fairly accurate since the landmarks used in this study are derived from well- demarcated outlines in the maxilla and mandible, i.e., premaxilla and symphysis respectively, and point $C$, if located within a radius of $2 \mathrm{~mm}$, does not affect the DR angle (Figs 2 to 4 ). Also, templates are used to derive the landmarks, which will further reduce the operator bias. The landmarks used in this study have been proved to be stable over a period of time. Point $\mathrm{M}$ and point $\mathrm{G}$ have been used to assess the growth vector of maxilla and mandible respectively, which in itself determines the stability of these points even during the active growth periods. ${ }^{15,17}$ Therefore, the reproducibility of these points would be quite accurate. Also, all the points used in this study have been used effectively in the past by various authors to derive cephalometric norms. ${ }^{11-14}$

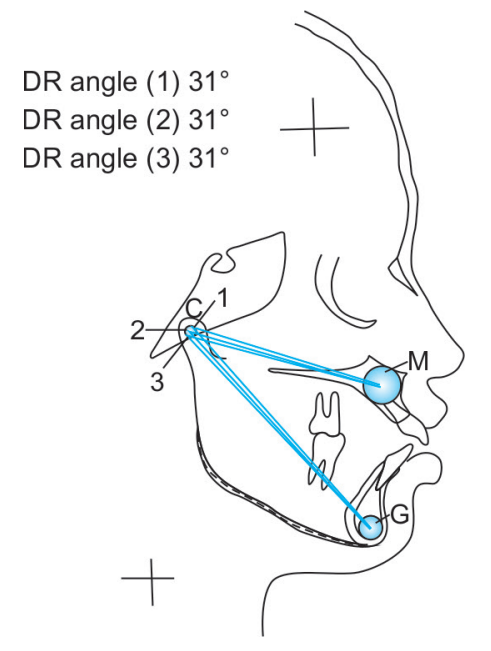

Fig. 3: Location of point $C$ in a radius of $2 \mathrm{~mm}$ circle from true center of the condyle in an average grower does not affect the DR angle 


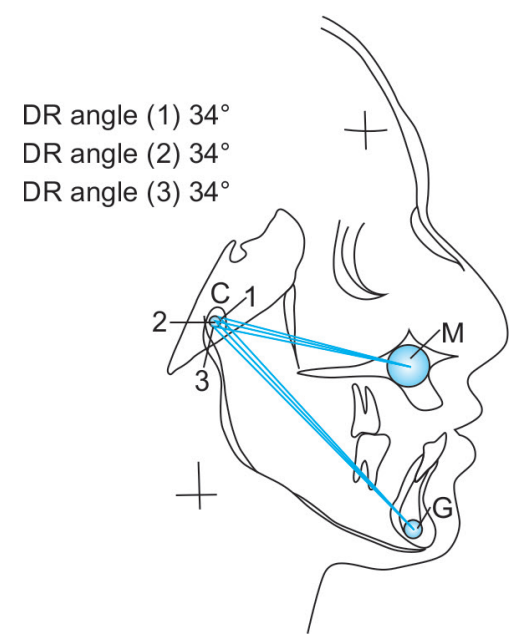

Fig. 4: Location of point $C$ in a radius of $2 \mathrm{~mm}$ circle from true center of the condyle in a vertical grower does not affect the DR angle

Although it is a valuable parameter in diagnosis of the vertical skeletal patterns of an individual, clinician should not totally disregard the previously established cephalometric measurements for the diagnosis of the vertical skeletal pattern of an individual. Rather, the DR angle will enrich the current cephalometric tools available to the clinician and enable the clinician to accurately diagnose and plan the treatment for any orthodontic patient. Any clinician should be aware of as many cephalometric analyses as possible but should use them cautiously and appropriately.

\section{CONCLUSION}

This study was done to develop a new parameter, the DR angle to evaluate the vertical skeletal patterns and it can be concluded that:

- The DR angle enables clinicians to assess the vertical skeletal pattern efficiently, therefore aiding in accurate diagnosis and treatment planning.

- No statistically significant differences exist between the mean DR angle values of males and female.

- Cephalometric evaluation of young adults shows that, the DR angle below $28.5^{\circ}$ indicates a horizontal growth pattern, between 28.5 and $32.5^{\circ}$ indicates an average growth pattern, and above $32.5^{\circ}$ indicates a vertical growth pattern.

\section{REFERENCES}

1. van Limborgh J. A new view of the control of the morphogenesis of the skull. Acta Morphol Neerl Scand 1970 Nov;8(2): 143-160.

2. van Limborgh J. The role of genetic and local environmental factors in the control of postnatal craniofacial morphogenesis. Acta Morphol Neerl Scand 1972 Oct;10(1):37-47.

3. Sassouni V. A classification of skeletal facial types. Am J Orthod 1969 Feb;55(2):109-123.

4. Tweed $\mathrm{CH}$. The Frankfort mandibular plane angle in orthodontic diagnosis, classification, treatment planning and prognosis. Am J Orthod Oral Sur 1946 Apr;32:175-230.

5. Steiner CC. Cephalometrics for you and me. Am J Orthod 1953;39:729-755.

6. Downs WB. Variations in facial relationships, their significance in analysis and treatment planning. Am J Orthod 1948 Oct;34(10):812-840.

7. McNamara JA Jr. A method of cephalometric evaluation. Am J Orthod 1984 Dec;86(6):449-469.

8. Jarabak JR, Fizzell JA. Technique and treatment with light-wire edgewise appliances, 2nd ed. Saint Louis, MO:CV Mosby Co;1972:277-379.

9. Rizwan M, Mascarenhas R, Husain A. Reliability of the existing vertical dysplasia indicators in assessing a definitive Growth Pattern. AmJOrthod 2011Dec 16:1-5.

10. Rizwan M, Mascarenhas R. A new parameter for assessing vertical skeletal discrepancies: The R angle. Am J Orthod 2013 Jun 16:1-7.

11. Nanda RS, Merill RM. Cephalomteric assessment of sagittal relationships between maxilla and mandible. Am J Orthod Dentofacial Orthop 1994 Apr;105(4):328-344.

12. Neela PK, Mascarenhas R, Husain A. A new sagittal dysplasia indicator: the yen angle. World J Orthod 2009 Summer;10(2): 147-151.

13. Bhad WA, Nayak S, Doshi UH. A new approach of assessing sagittal dysplasia: the W angle. Eur J Orthod. 2013 Feb;35(1): 66-70.

14. Dave HB, Gill V, Rai D, Reddy YNN. The HBN Angle. J Indian Orthod Soc 2015;49(2):79-84.

15. Braun S, Rudman RT, Murdoch HJ, Hicken S, Kittleson R, Ferguson DJ. C-axis: A growth vector for the maxilla. Angle Orthod 1999 Dec;69(6):539-542.

16. Baik CY, Ververidou M. A new approach of assessing sagittal discrepancies: The beta angle. Am J Orthod Dentofacial Orthop 2004 Jul;126(1):100-105.

17. Braun S, Kittleson R, Kim K. The G-Axis: A growth vector for the mandible. Angle Orthod 2004 Jun;74:328-331.

18. Metz CE. Basic principles of ROC analysis. Semin Nucl Med 1978 Oct;8(4):283-298. 